\title{
Measuring sustained attention after traumatic brain injury: Differences in key findings from the sustained attention to response task (SART)
}

John Whyte

Thomas Jefferson University and Albert Einstein Healthcare Network

Patricia Grieb-Neff

Albert Einstein Healthcare Network

Christopher Gantz

Albert Einstein Healthcare Network

Marcia Polansky

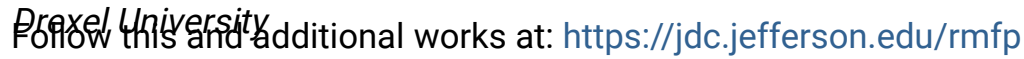

Part of the Neurology Commons

\section{Let us know how access to this document benefits you}

\section{Recommended Citation}

Whyte, John; Grieb-Neff, Patricia; Gantz, Christopher; and Polansky, Marcia, "Measuring

sustained attention after traumatic brain injury: Differences in key findings from the sustained attention to response task (SART)" (2006). Department of Rehabilitation Medicine Faculty

Papers. Paper 1.

https://jdc.jefferson.edu/rmfp/1

This Article is brought to you for free and open access by the Jefferson Digital Commons. The Jefferson Digital Commons is a service of Thomas Jefferson University's Center for Teaching and Learning (CTL). The Commons is a showcase for Jefferson books and journals, peer-reviewed scholarly publications, unique historical collections from the University archives, and teaching tools. The Jefferson Digital Commons allows researchers and interested readers anywhere in the world to learn about and keep up to date with Jefferson scholarship. This article has been accepted for inclusion in Department of Rehabilitation Medicine Faculty Papers by an authorized administrator of the Jefferson Digital Commons. For more information, please contact: JeffersonDigitalCommons@jefferson.edu. 


\title{
Measuring sustained attention after traumatic brain injury: Differences in key findings from the sustained attention to response task (SART)
}

\author{
John Whyte ${ }^{\mathrm{a}, \mathrm{b}, *}$, Patricia Grieb-Neff ${ }^{\mathrm{a}}$, Christopher Gantz ${ }^{\mathrm{a}}$, Marcia Polansky ${ }^{\mathrm{c}}$ \\ ${ }^{a}$ Moss Rehabilitation Research Institute, Albert Einstein Healthcare Network, Philadelphia, PA, United States \\ ${ }^{\mathrm{b}}$ Department of Rehabilitation Medicine, Thomas Jefferson University, Philadelphia, PA, United States \\ ${ }^{\mathrm{c}}$ Department of Biostatistics, Drexel University, Philadelphia, PA, United States
}

*Corresponding author at: Moss Rehabilitation Research Institute, 1200 W. Tabor Road, Suite 213, Philadelphia, PA 19141, United States. Tel.: +1 215456 5925; fax: +1 2154565926.

E-mail address: jwhyte@einstein.edu (J. Whyte).

\begin{abstract}
Clinical reports after traumatic brain injury (TBI) suggest frequent difficulties with sustained attention, but their objective measurement has proved difficult. In 1997, Robertson and colleagues reported on a new sustained attention assessment tool, the sustained attention to response task (SART). Individuals with TBI were reported to produce more errors of commission on the SART than control participants, and both groups showed a relationship between SART errors and everyday lapses of attention as measured by the cognitive failures questionnaire (CFQ). Although few direct replications of these findings have been reported, the SART has been used widely as a measure of sustained attention in TBI, in normal controls, and in various other clinical samples.

As part of a program of research on attention in TBI, we administered the SART and the CFQ to a sample of 34 survivors of moderate to severe TBI and to 35 control participants. CFQ scores reported by significant others showed clear group differences in everyday lapses of attention. Despite this, group differences in SART errors of commission were small and non-significant, and the correlations between SART errors and CFQ scores were small within both groups. Further analyses excluding participants with invalid score profiles, or restricting the analysis to the first performance of the SART failed to alter the results.
\end{abstract}

These findings suggest that more research is needed to establish the validity of the SART as a measure of sustained attention after TBI, and to determine under what circumstances the original findings hold.

Keywords: Brain injuries; Attention; Vigilance; Sustained attention to response task (SART) 


\section{Introduction}

Attention deficits are common after traumatic brain injury (TBI), (Dikmen, Machamer, Winn, \& Temkin, 1995; Jacobs, 1988; McKinlay, Brooks, Bond, Martinage, \& Marshall, 1981) but their objective measurement has proved challenging. Difficulties with sustained attention, in particular, are frequently noted clinically, and a number of studies have attempted to measure this deficit using traditional vigilance tasks, in which a subject detects (typically) infrequent targets over several minutes' time (Parasuraman, 1984). In such tasks, the slope of either reaction time (slowing) or accuracy (declining) over time may be steeper after TBI, (Melamed, Rahamani, Greenstein, Groswasser, \& Najenson, 1985; Whyte, Polansky, Fleming, Coslett, \& Cavallucci, 1995) but this finding has not been consistent (Brouwer \& van Wolffelaar, 1985; Buchtel, 1987).

In 1997, Robertson and colleagues reported on a new sustained attention measure - the "sustained attention to response task" (SART), (Robertson, Manly, Andrade, Baddeley, \& Yiend, 1997) which differs from typical vigilance tasks in being fairly short $(4.3 \mathrm{~min})$, and in requiring very frequent responses $(89 \%$ of trials) and rare withholding of responses. In brief, this task involves the presentation of 225 digits at the center of a computer screen in random order, with an ISI of $1150 \mathrm{~ms}$. The subject's task is to press a response key as quickly as possible in response to every digit except " 3 ." Robertson and colleagues argue that withholding responses to the infrequent non-targets requires controlled (i.e., attention-demanding) processing, to combat the tendency to automatize responding to the more frequent targets. Errors of commission (i.e., responding to " 3 " stimuli) are thought to be due to lapses of attention, reflecting an impairment of sustained attention.

The authors of the SART make two key claims to support its validity as a measure of sustained attention in TBI:

1. Scores on the SART differ significantly between individuals with TBI and control subjects, with the TBI subjects making more errors of commission.

2. SART errors of commission are correlated, in both normal control subjects and those with TBI, with scores provided by significant others on the Cognitive Failures Questionnaire (CFQ), (Broadbent, Cooper, FitzGerald, \& Parkes, 1982)a measure of everyday "lapses of attention."

The first claim is important if this task is argued to be sensitive to a clinically salient deficit that is prevalent in TBI but not in controls. The second claim is important to support the clinical and ecological validity of this task as a measure specifically of lapses in attention that can be seen in everyday life.

A number of studies have used the SART as a measure of sustained attention in TBI, (Chan, 2001; Chan, 2002; Chan, Hoosain, Lee, Fan, \& Fong, 2003; Dockree et al., 2004) and in other subject groups (Dale, Naik, \& Thompson, 2003; David et al., 2002; Farrin, Hull, Unwin, Wykes, \& David, 2003; Hull et al., 2003; Manly, Lewis, Robertson, Watson, \& Datta, 2002; Manly, Robertson, Galloway, \& Hawkins, 1999; Thompson, Rushman, Fox, Lloyd, \& Atcheson, 2002; Wallace, Kass, \& Stanny, 2001 ), and have studied the PET correlates of this task (Manly et al., 2003). A more recent, fixed-order variation on the task (SARTFixed), is reported to produce fewer errors of commission by both TBI and control subjects, but with less overlap in the error rates of the two groups (Manly et al., 2003). Despite the interest in and dissemination of the original SART task, replications of the key original findings have been few.

As noted in Table 1, of the studies that compared errors of commission between individuals with TBI and control participants, one clearly replicated the group difference reported by Robertson and colleagues, 
(Manly et al., 2003) while another did not, (Chan, 2001) although TBI participants in this latter study had mild injuries. Two other studies produced equivocal results (Chan, 2002; Chan et al., 2003; Dockree et al., 2004).

We identified only two studies that examined the relationship between SART errors of commission and everyday lapses of attention as measured by the CFQ, in individuals with TBI, normal control participants, or both. In a study by Manly and colleagues, participants split into high and low CFQ score groups differed in their SART errors of commission (Manly et al., 1999). Wallace et al., however, found no correlation between self-reported CFQ scores and SART errors of commission in a group of university students (Wallace et al., 2001). Therefore, we attempted to replicate the original findings of Robertson et al.

\section{Methods}

\subsection{Study participants}

Participants with TBI whose data are reported here were involved in a larger study on methylphenidate and attention (Alban, Hopson, Ly, \& Whyte, 2004; Whyte et al., 2004). Data from control participants have not been previously reported. In brief, participants between the ages 16 and 60 with a history of moderate or severe non-penetrating TBI at least 3 months prior to testing were recruited from a variety of clinical sources and research registries. Severity was defined by a Glasgow Coma Scale (GCS) score less than 12 (generally recorded in the Emergency Department), prospectively documented post-traumatic amnesia (PTA) of greater than $1 \mathrm{~h}$, and/or focal abnormality on a neuroimaging study. A subjective complaint of attention difficulties by the participant, treating clinician, or caregiver was also required. Participants received no structured treatment of these attention complaints during the study period, other than the study drug. Potential participants were excluded for pre-injury neurologic disease, psychosis, major affective disorder, mental retardation, or attention deficit hyperactivity disorder, current abuse of alcohol or recreational drugs, or cumulative use of these substances judged sufficient to contribute independently to cognitive impairment. Those taking psychoactive medications other than anti-convulsants were also excluded. Control participants who had never sustained a traumatic injury resulting in unconsciousness were recruited from hospital staff, social contacts of the participants with TBI, and through public advertising. The same exclusion criteria were applied. TBI and control participants were well matched for demographics and estimated premorbid IQ, as shown in Table 2.

\subsection{Procedure}

SART data were collected weekly at the same time of day, for 2 weeks (controls) or 6 weeks (participants with TBI), as part of a much larger data acquisition effort involving multiple other tasks (Whyte et al., 2004). The SART was administered via a Macintosh computer, programmed with Psyscope, and modified to record the responses with a button box for more precise RT timing. The task lasted under 5 min. Those with TBI received methylphenidate $(\mathrm{M})$ or placebo $(\mathrm{P})$ in alternating 6-day epochs (counterbalanced for MPMPMP and PMPMPM orders) with one washout day in between. Controls received no medication. A significant other also provided weekly CFQ (Broadbent et al., 1982) ratings on each participant. The CFQ assesses the frequency of everyday lapses in attention using a five point Likert type scale, ranging from very often to never, with higher scores indicating more difficulties. For participants with TBI, only the SART and CFQ scores from placebo weeks were used in the analyses.

\subsection{Data analysis}

Comparability of participants with and without TBI was assessed using $\chi^{2}$ tests for categorical and $T$-tests for continuous variables. Histograms of SART RT data for each participant, collapsed across the two (controls) or three (placebo sessions of individuals with TBI) sessions revealed the expected skewed-to-the- 
right RT distributions in all control participants and most participants with TBI. In some participants with TBI, however, the right side of the distribution stopped abruptly at $1150 \mathrm{~ms}$ (the ISI), rather than tailing off, indicating a proportion of late responses that were recorded as omissions on the trial in question and premature responses on the subsequent trial, thus invalidating both RT and accuracy. Representative distributions are shown in Fig. 1. A decision rule was used to eliminate these "invalid" participants from subsequent analyses. ${ }^{1}$ In this report, we focus on those with valid data $(n=26)$, but also display to results for the whole sample $(n=34)$, to allow comparison with other investigators that may not have excluded such individuals.

Performance on the SART was assessed by the number of commission and omission errors. These error rates and CFQ scores were averaged over the three placebo sessions for each participant with TBI, and over the two testing sessions for controls. Additional analyses, based on only the first session of data for each subject, were also done to explore the confounding effects of practice and possible drug carry over effects. $T$ tests were used to investigate group differences in error rates and CFQ scores. Paired $T$ tests were used to assess changes in performance from session to session. Pearson correlations were used to compare the relationships between the SART variables and CFQ scores within groups. ${ }^{2}$ Effect sizes (Cohen's d) were also calculated to facilitate comparison of results between our study and others' differing in sample size (Cohen, 1988).

\section{Results}

Because this study was not originally designed to replicate the SART findings, we are aware of the possible confounding effects of repeated practice and drug carry over effects, inherent in our study design that might have differentially affected the two groups. Below we report first on the data analysis that makes use of all the valid data from both groups. However, we follow this with an analysis that seeks to eliminate the possible influence of these confounds.

There was no significant group difference in errors of commission or errors of omission when this analysis was performed using all of the sessions of those with valid data, and the effect size for group with respect to errors of commission was zero, as shown in Table 3. As expected, RT was significantly slower in those with TBI, despite elimination of the most impaired individuals. CFQ scores differed significantly between groups, with a moderate to large effect size; those with TBI were reported to have more attentional lapses. The correlation between CFQ scores and SART errors of commission did not approach significance in either group, as shown in Table 3.

A comparison of the full sample of TBI participants (including those with invalid profiles) with controls yielded similar findings with the exception of significantly greater errors of omission in those with TBI, as might be expected from the data recording error we identified. CFQ and RT differences between groups were even more dramatic, as expected from including more severely impaired participants. However, errors of commission again showed no significant group differences, and the relationship between errors of commission and CFQ scores remained negligible.

\footnotetext{
${ }^{1}$ Details of the rule for excluding invalid subjects are available from the authors. In brief, histograms grouped by visual inspection were used to identify a proportion of trials with RTs $>1000 \mathrm{~ms}$ which produced the same grouping. Those excluded had more severe current disability levels as measured by the disability rating scale, and has slower RTs on a range of other assessment tasks not reported here. No control subjects demonstrated an invalid profile.

${ }^{2}$ Analysis were replicated with nonparametric methods, but did not alter the findings.
} 
As noted above, these analyses were conducted on performance scores averaged over two (controls) or three (participants with TBI) sessions, whereas prior studies have generally been based on a single administration of both SART and CFQ. Analysis of changes in errors of commission with practice showed a significant reduction from session 1 to session 2 among controls (mean of 6.37 versus $5.03, \mathrm{P}<0.01$ ), and from session 1 to session 3 in patients (session 2 for these individuals was on methylphenidate) (mean of 7.3 versus 5.1, $\mathrm{P}<0.01)$. To control both for these practice effects ${ }^{3}$ and for the possibility of carryover effects of the study drug, we repeated the analyses using only the true first data collection session for both subject groups. Since the first session was conducted on methylphenidate for half of the participants with TBI, the valid TBI sample for this analysis was reduced by half (to 13). This sample of 13 had not yet been exposed to methylphenidate, removing persistent residual treatment effects as a potential confound.

The remaining participants with TBI remained demographically similar to controls (See Table 2). Because of the reduced sample, we focus here on effect sizes rather than $p$ values. Differences in errors of commission remain small, although the effect size was slightly larger than when computed across all sessions ( 0.25 versus 0$)$ (See Table 4$)$. Group differences in errors of omission were also small. In contrast, differences in RT and CFQ between groups remained substantial (effect sizes of 0.84 and 0.52 , respectively, quite comparable to the values from the averaged sessions). Correlations between SART errors of commission and CFQ scores remained small in both groups.

\section{Discussion}

Our research failed to replicate either of the key original findings by Robertson and colleagues - that individuals with TBI make more errors of commission on the SART than uninjured controls, and that the number of such errors in both groups is correlated with the severity of everyday lapses of attention, as measured by significant others' reports on the CFQ. Errors of omission, which were not hypothesized to reflect a sustained attention deficit, differed between groups only when TBI participants with invalid data were included. Given the discrepancy between the original report and our attempted replication, it is important to consider study limitations and differences between our methods and those of Robertson and colleagues, that might potentially explain the different pattern of results.

One possibility is that our study lacked sufficient statistical power to identify these patterns. This appears unlikely. For the assessment of a group difference in errors of commission, Robertson's study involved 22 individuals with TBI and 17 controls, in comparison to our sample of 26 (valid) individuals with TBI and 35 controls. For the analysis of correlations between errors of commission and CFQ scores, Robertson used data from 21 individuals with TBI and 75 control participants, whereas we again used data from 25 individuals with TBI and 32 controls. Moreover, our calculation of effect sizes and correlations suggests that the group difference in SART errors of commission (effect sizes 0-0.25 for the comparison of TBI participants with valid data and controls) and the amount of variance in CFQ scores explained by SART errors (correlations of $0.11-0.20$ for individuals with TBI and -0.05 to -0.09 for control participants) are small in magnitude, not simply that we lacked statistical power. Moreover, histograms showing the rates of errors of commission in the two groups show substantial overlap (See Fig. 2).

Another possible explanation of the discrepancy could be differences in our participants. That is, if our participants with TBI had milder injuries or had undergone more substantial recovery, they might differ less from controls, particularly since we excluded our most impaired participants because of invalid SART data.

\footnotetext{
${ }^{3}$ It is worth noting that Robertson et al attribute SART errors of commission to the development of automatic response tendencies, perhaps predicting that such errors might become more prevalent rather than less so with practice.
} 
However, our TBI participants do not appear to be less impaired than those of Robertson et al. Based on duration of post-traumatic amnesia, our sample contained 22/23 (>95\%) participants with very severe or extremely severe injuries, compared to 16/32 (50\%) in the Robertson study. It does appear, however, that our sample was more chronic (median time since injury nearly 3 years) than those studied by Robertson (918 months), but certainly not fully recovered. Our TBI participants had continued disability, as measured by the DRS, as well as subjective complaints of attention deficits. In fact, our participants with TBI performed relatively similarly to those in Robertson's study, while our control participants performed somewhat worse than theirs. In addition, our groups differed significantly in CFQ scores, suggesting that our participants with TBI did suffer from the clinical deficit that the SART is intending to measure. Moreover, differences in severity of injury or the nature of our control participants could explain the lack of a group difference in SART commission errors, but not the negligible relationship between SART errors and CFQ scores within each group. Since anxiety and depression have been shown previously to contribute to SART performance (Chan, 2002; Chan et al., 2003), it is possible that our samples differed from Robertson's along these dimensions. We cannot, however, verify this, since neither our study nor theirs measured these emotional states.

We analyzed our data both including and excluding participants with invalid SART data, to explore the possibility that Robertson's findings might have been based, in part, on the inclusion of participants with undetected invalid data. However, as shown in Table 3, the inclusion of those individuals produced larger group differences in errors of omission, but not in errors of commission. We also assessed whether differences might be due to a drop in errors of commission during practice, since our participants performed the SART on multiple occasions. However, although practice effects were seen in SART performance, restriction of the analysis to the initial testing session did not substantially alter the results. Neither does the discrepancy appear to be attributable to drug carryover effects, since restricting the analysis to those whose initial session of data collection was conducted on placebo did not substantially alter the results. Moreover, the plasma half-life of methylphenidate is $1.5-2.5 \mathrm{~h}$, making such carryover effects relatively unlikely (Challman \& Lipsky, 2000). It remains possible, however, that patients' SART performance even in the initial session was elevated by a placebo effect associated with mere participation in a drug study.

Despite considering a number of differences in participants and methodology between our study and Robertson et al.'s, we were not able to identify a reason for the key differences in our findings.

Nevertheless, since a number of researchers have adopted the SART as a measure of sustained attention, we believe it is important to report the differences in findings and to explore their source further, in order to more precisely define the circumstances under which the SART validly measures sustained attention. In addition, it is important for investigators using the SART, particularly with clinical populations, to be aware of the validity problem associated with slow responders, and to screen their RT distributions to ensure that such problems do not contaminate their results.

After adopting the original SART for our research, the fixed SART was reported to produce lower rates of errors of commission, but improved discrimination between individuals with TBI and controls (Manly et al., 2003). It has been reported that the fixed SART reduces reliance on inhibition of ongoing responses and more purely measures sustained attention (Bellgrove, Hawi, Kirley, Gill, \& Robertson, 2005). Thus, it may be that results from the fixed SART can be replicated more reliably. Future research on both versions of the task should verify the group differences in error rates and their relationship to everyday errors of attention and clinically important deficits.

\section{Conclusion}

We were unable to replicate two key findings related to the original version of the SART - that errors of commission differ between individuals with moderate and severe TBI, and matched controls, and that SART commission error rates are correlated with everyday attention difficulties as measured by the CFQ. Although 
the reason for the difference in results between our laboratory that of Robertson et al is elusive, additional research should be done on the SART and/or the newer fixed SART to further define its validity in both respects.

\section{Acknowledgments}

This research was supported, in part, by grant \#R01NS39163 from the National Institute on Neurological Diseases and Stroke, and grant \# R24HD39621 from the National Center for Medical Rehabilitation Research, at the National Institute on Child Health and Human Development, both at the National Institutes of Health. We are grateful to many individuals who assisted in the research. Joseph Alban, Natosha Bailey, Monica Hopson, and Vonetta Drakes, managed participant recruitment and testing. Adelyn Brecher, Anne Hammond, Karen Hawkey, Andrea Laborde, Walter Lewis, Nathaniel Mayer, Jeanne Pelensky, Rosadele Plumari, all helped to identify and refer eligible participants. Mary Czerniak assisted in the preparation of the manuscript. Most importantly, we wish to thank the participants and their families for participation in this study.

\section{References}

Alban, J. P., Hopson, M. M., Ly, V., \& Whyte, J. (2004). Effect of methylphenidate on vital signs and adverse effects in adults with traumatic brain injury. American Journal of Physical Medicine and Rehabilitation, 83, 131-137.

Bellgrove, M. A., Hawi, Z., Kirley, A., Gill, M., \& Robertson, I. H. (2005). Dissecting the attention deficit hyperactivity disorder (ADHD) phenotype: Sustained attention, response variability and spatial asymmetries in relation to dopamine transporter (DAT1) genotype. Neuropsychologia, 43, 1847-1857.

Broadbent, D. E., Cooper, P. F., FitzGerald, P., \& Parkes, K. R. (1982). The cognitive failures questionnaire (CFQ) and its correlates. British Journal of Clinical Psychology, 21, 1-16.

Brouwer, W. H., \& van Wolffelaar, P. C. (1985). Sustained attention and sustained effort after closed head injury: Detection and 0.10 heart rate variability in a low even rate vigilance task. Cortex, 1, 1-12.

Buchtel, H. A. (1987). Attention and vigilance after head trauma. New York: Oxford University Press. Challman, T. D., \& Lipsky, J. J. (2000). Methylphenidate: Its pharmacology and uses. Mayo Clinic Proceedings, 75, 711-721.

Chan, R. C. K. (2001). A further study on the sustained attention response to task (SART): The effect of age, gender and education. Brain Injury, 15(9), 819-829.

Chan, R. C. K. (2002). Attentional deficits in patients with persisting postconcussive complaints: A general deficit or specific component deficit? Journal of Clinical and Experimental Neuropsychology, 24(8), 1081-1093.

Chan, R. C. K., Hoosain, R., Lee, T. M. C., Fan, Y. W., \& Fong, W. (2003). Are there sub-types of attentional deficits in patients with persisting post-concussive symptoms? A cluster analytical study. Brain Injury, 17(2), 131-148.

Cohen, J. (1988). The t test for means. Hillsdale, NJ: Lawrence Earlbaum Associates.

Dale, M. T., Naik, R., \& Thompson, J. P. (2003). Using the sustained attention to response task after major surgery under general anaesthesia. British Journal of Anaesthesia, 824-825.

David, A. S., Farrin, L., Hull, L., Unwin, C., Wessely, S., \& Wykes, T. (2002). Cognitive functioning and disturbances of mood in UK veterans of the Persian Gulf War: A comparative study. Psychological Medicine, 32, 1357-1370.

Dikmen, S. S., Machamer, J. E., Winn, H. R., \& Temkin, N. R. (1995). Neuropsychological outcome at 1year post head injury. Neuropsychology, 9(1), 80-90.

Dockree, P. M., Kelly, S. P., Roche, R. A. P., Hogan, M. J., Reilly, R. B., \& Robertson, I. H. (2004). Behavioural and physiological impairments of sustained attention after traumatic brain injury. Cognitive Brain Research, 20(3), 403-414.

Farrin, L., Hull, L., Unwin, C., Wykes, T., \& David, A. (2003). Effects of depressed mood on objective and subjective measures of attention. Journal of Neuropsychiatry and Clinical Neurosciences, 15(1), 98-104.

Hull, L., Farrin, L., Unwin, C., Everitt, B., Wykes, T., \& David, A. S. (2003). Anger, psychopathology and cognitive inhibition: A study of UK servicemen. Personality and Individual Differences, 35, 1211-1226. 
Jacobs, H. (1988). The Los Angeles head injury survey: Procedures and initial findings. Archives of Physical Medicine and Rehabilitation, 69, 425-431.

Manly, T., Lewis, G. H., Robertson, I. H., Watson, P. C., \& Datta, A. K. (2002). Coffee in the cornflakes: Time-of-day as a modulator of executive response control. Neuropsychologia, 40, 1-6.

Manly, T., Owen, A. M., McAvinue, L., Datta, A., Lewis, G. H., Scott, S. K., Rorden, C., Pickard, J., \& Robertson, I. H. (2003). Enhancing the sensitivity of a sustained attention task to frontal damage:

Convergent clinical and functional imaging evidence. Neurocase, 9(4), 340-349.

Manly, T., Robertson, I. H., Galloway, M., \& Hawkins, K. (1999). The absent mind: Further investigations of sustained attention to response. Neuropsychologia, 37, 661-670.

McKinlay, W., Brooks, D., Bond, M., Martinage, D., \& Marshall, M. (1981). The short term outcome of severe blunt head injury as reported by relatives of the injured persons. Journal of Neurology, Neurosurgery and Psychiatry, 44, 527.

Melamed, S., Rahamani, L., Greenstein, Y., Groswasser, Z., \& Najenson, T. (1985). Divided attention in brain injured patients. Scandinavian Journal of Rehabilitation Medicine, 12, 16-20.

Parasuraman, R. (1984). Sustained attention in detection and discrimination. Orlando: Academic Press, Inc.

Robertson, I. H., Manly, T., Andrade, J., Baddeley, B. T., \& Yiend, J. (1997). 'Oops!': Performance correlates of everyday attentional failures in traumatic brain injured and normal subjects. Neuropsychologia, 35(6), 747-758.

Thompson, J. P., Rushman, S. C., Fox, A. J., Lloyd, A. J., \& Atcheson, R. A. (2002). Using the sustained attention to response test to detect cognitive dysfunction after day case surgery. European Journal of Anaesthesiology, 18(8), 585-588.

Wallace, J., \& Vodanovich, S. (2003). Can accidents and industrial mishaps be predicted? Further investigation into the relationship between cognitive failure and reports of accidents. Journal of Business and Psychology, 17(4), 503-514.

Wallace, J. C., Kass, S. J., \& Stanny, C. (2001). Predicting performance in 'Go' situations: A new use for the cognitive failures questionnaire? North American Journal of Psychology, 3(3), 481-490.

Whyte, J., Hart, T., Vaccaro, M., Grieb-Neff, P., Risser, A., Polansky, M., \& Coslet, H. B. (2004). The effects of methylphenidate on attention deficits after traumatic brain injury: A multi-dimensional randomized controlled trial. American Journal of Physical Medicine and Rehabilitation, 83(6), 401-420.

Whyte, J., Polansky, M., Fleming, M., Coslett, H., \& Cavallucci, C. (1995). Sustained arousal and attention after traumatic brain injury. Neuropsychologia, 33(7), 797-813. 
Table 1

Key Studies on the SART

\begin{tabular}{|c|c|c|c|c|c|}
\hline Authors & Subjects & Procedure & Results & $\begin{array}{l}\text { Support for } \\
\text { TBI/control difference } \\
\text { in SART }\end{array}$ & $\begin{array}{l}\text { Support for } \\
\text { relationship between } \\
\text { SART and CFQ }\end{array}$ \\
\hline $\begin{array}{l}\text { Manley et al. } \\
\text { (1999) }\end{array}$ & 60 Controls & $\begin{array}{l}\text { Ss divided into two } \\
\text { groups based on CFQ } \\
\text { scores; SART and } \\
\text { other go/no-go tasks } \\
\text { w/different target } \\
\text { frequency done }\end{array}$ & $\begin{array}{l}\text { Low CFQ group made more errors of } \\
\text { commission than high CFQ group, but only in } \\
\text { the SART }\end{array}$ & -- & Yes (controls) \\
\hline $\begin{array}{l}\text { Manley et al. } \\
\text { (2003) }\end{array}$ & $\begin{array}{l}19 \text { Individuals with TBI } \\
\text { (mostly severe), Random } \\
\text { and fixed SART } 16 \\
\text { controls }\end{array}$ & $\begin{array}{l}\text { Random and fixed } \\
\text { SART }\end{array}$ & $\begin{array}{l}\text { TBI Ss made more errors of commission on } \\
\text { both tasks than controls; both groups made } \\
\text { fewer errors on fixed SART; TBI Ss also made } \\
\text { more errors of omission }\end{array}$ & Yes & -- \\
\hline $\begin{array}{l}\text { Chan }(2002 \text {, } \\
\text { Chan et al. } \\
(2003)\end{array}$ & $\begin{array}{l}\text { Individuals with "TBI" } \\
\text { (>80\% had no Random } \\
\text { SART and several al. } \\
\text { (2003) PTA, }>60 \% \text { had } \\
\text { no LOC) other tasks }\end{array}$ & $\begin{array}{l}\text { Random SART and } \\
\text { several other tasks }\end{array}$ & $\begin{array}{l}\text { TBI pts significantly different from controls in } \\
\text { total errors and errors of commission, but not } \\
\text { after controlling for depression } \& \text { anxiety }\end{array}$ & No? & -- \\
\hline $\begin{array}{l}\text { Wallace and } \\
\text { Vodanovich } \\
(2003)\end{array}$ & 151 University students & $\begin{array}{l}\text { Random SART and } \\
\text { CFQ }\end{array}$ & $\begin{array}{l}\text { No significant relationship between SART } \\
\text { errors of commission and CFQ self-report } \\
\text { (errors of omission correlated w/the CFQ } \\
\text { memory subscale) }\end{array}$ & -- & No \\
\hline Chan (2001) & $\begin{array}{l}30 \text { Individuals with mild } \\
\text { TBI, } 68 \text { controls }\end{array}$ & Random SART & $\begin{array}{l}\text { TBI Ss made more total errors, but errors of } \\
\text { commission not significantly different }\end{array}$ & No & -- \\
\hline $\begin{array}{l}\text { Dockree et al. } \\
\text { (2004) }\end{array}$ & $\begin{array}{l}10 \text { Individuals with TBI } \\
\text { (mostly severe), } 10 \\
\text { controls }\end{array}$ & $\begin{array}{l}18 \text { min version of } \\
\text { Random SART, CFQ }\end{array}$ & $\begin{array}{l}\text { TBI Ss made significantly more SART } \\
\text { commission errors and had worse CFQ scores. } \\
\text { Non-significant trend for greater anxiety and } \\
\text { depression in TBI, not covaried in SART error } \\
\text { analysis }\end{array}$ & Yes? & -- \\
\hline $\begin{array}{l}\text { Farrin et al. } \\
(2003)\end{array}$ & $\begin{array}{l}102 \text { British soldiers } \\
\text { w/and w/o depression }\end{array}$ & Random SART, CFQ & $\begin{array}{l}\text { CFQ scores were moderately correlated } \\
\text { w/SART errors of commission }(p=0.34) \text {; both } \\
\text { SART errors and CFQ scores were } \\
\text { significantly greater in depressed subjects; } \\
\text { SART/CFQ relationship non-significant after } \\
\text { controlling for depression }\end{array}$ & -- & No? \\
\hline
\end{tabular}




\section{Table 2}

Characteristics of participants

\begin{tabular}{|c|c|c|c|c|c|}
\hline & Controls & Patients with valid data & $p$ & $\begin{array}{l}\text { Patients with valid data for } \\
\text { first true placebo session }\end{array}$ & $\underline{p}$ \\
\hline$n$ & 35 & 26 & & 13 & \\
\hline \multicolumn{6}{|l|}{ Demographic characteristics } \\
\hline \multicolumn{6}{|l|}{ Age (years) } \\
\hline Mean & 37 & 36 & \multirow[t]{2}{*}{0.78} & 37 & \multirow[t]{2}{*}{0.91} \\
\hline Range & $17-55$ & $20-55$ & & $24-55$ & \\
\hline \multicolumn{3}{|l|}{ Sex, $n(\%)$} & \multirow{3}{*}{0.75} & & \multirow[t]{3}{*}{0.92} \\
\hline Male & $30(86)$ & $23(88)$ & & $11(85)$ & \\
\hline Female & $5(14)$ & $3(12)$ & & $2(15)$ & \\
\hline \multicolumn{3}{|l|}{ Ethnicity, n (\%) } & \multirow[t]{4}{*}{0.63} & & \multirow[t]{4}{*}{0.44} \\
\hline White & $21(60)$ & $18(69)$ & & $10(77)$ & \\
\hline African American & $12(34)$ & $6(23)$ & & $2(15)$ & \\
\hline Hispanic & $2(6)$ & $2(8)$ & & $1(8)$ & \\
\hline \multicolumn{6}{|l|}{ Education (years) } \\
\hline Mean & 12.5 & 13 & \multirow{3}{*}{0.45} & & \multirow[t]{3}{*}{0.58} \\
\hline Median & 12 & 12 & & & \\
\hline Range & $8-17$ & $10-18$ & & & \\
\hline \multicolumn{6}{|l|}{ Estimated IQ } \\
\hline NAART estimate (mean, S.D.) & $101(10.6)$ & $98(11.3)$ & 0.26 & $99(12.3)$ & 0.66 \\
\hline Demographic regression formula & $101(8.3)$ & $103(9.6)$ & 0.41 & $103(10.3)$ & 0.54 \\
\hline \multicolumn{6}{|l|}{ Injury and disability characteristics } \\
\hline \multicolumn{6}{|l|}{ Estimated duration of PTA } \\
\hline Mild & \multicolumn{3}{|l|}{0} & \multicolumn{2}{|l|}{0} \\
\hline Moderate & \multicolumn{3}{|l|}{1} & \multicolumn{2}{|l|}{1} \\
\hline Severe & \multicolumn{3}{|l|}{0} & \multicolumn{2}{|l|}{0} \\
\hline Very severe & \multicolumn{3}{|l|}{3} & \multicolumn{2}{|l|}{1} \\
\hline Extremely severe & \multirow{2}{*}{\multicolumn{3}{|c|}{19}} & \multicolumn{2}{|l|}{10} \\
\hline \multicolumn{3}{|l|}{ Time post injury } & & & \\
\hline Range & \multicolumn{3}{|c|}{3.6 months -34.2 years } & \multirow{2}{*}{\multicolumn{2}{|c|}{$\begin{array}{l}3.6 \text { months }-34.2 \text { years } \\
3.9 \text { years }\end{array}$}} \\
\hline Median & 2.8 years & & & & \\
\hline
\end{tabular}


Table 3

Scores averaged across all sessions

\begin{tabular}{|c|c|c|c|c|c|c|c|c|c|c|c|c|c|c|c|c|}
\hline \multirow[t]{2}{*}{ Descriptive statistics } & \multicolumn{6}{|c|}{ TBI participants-valid data } & \multicolumn{6}{|c|}{ All TBI participants } & \multicolumn{4}{|c|}{ Uninjured control participants } \\
\hline & $n$ & Mean & Range & S.D. & $\begin{array}{l}\text { Effect } \\
\text { size }\end{array}$ & $p^{\mathrm{a}}$ & $n$ & Mean & Range & S.D. & $\begin{array}{l}\text { Effect } \\
\text { size }\end{array}$ & $p^{\mathrm{a}}$ & $n$ & Mean & Range & S.D. \\
\hline SART $_{\text {commission }}$ & 26 & 5.7 & $0-15.7$ & 4.5 & 0 & 0.99 & 34 & 6.8 & $0-17.3$ & 4.8 & 0.28 & 0.27 & 35 & 5.7 & $2-11.5$ & 3.1 \\
\hline $\mathrm{SART}_{\text {omission }}$ & 26 & 4.5 & $0-22.7$ & 5.2 & 0.08 & 0.75 & 34 & 12.8 & $0-77.7$ & 18.5 & 0.64 & 0.01 & 35 & 4 & $0-32$ & 7.3 \\
\hline SARTR $_{T}$ & 26 & 432 & $283-616$ & 78 & 0.83 & 0.002 & 34 & 465 & $283-643$ & 94 & 1.14 & $<.001$ & 35 & 370 & $245-541$ & 74 \\
\hline CFQ & 25 & 11.1 & $0-22$ & 6.2 & 0.62 & 0.03 & 32 & 12 & $0-22$ & 6 & 0.78 & 0.003 & 31 & 7.6 & $.5-23.5$ & 5.1 \\
\hline \multirow[t]{2}{*}{ Correlations } & \multicolumn{6}{|c|}{ TBI participants-valid data } & \multicolumn{6}{|c|}{ All TBI participants } & \multicolumn{4}{|c|}{ Uninjured control participants } \\
\hline & $n$ & $\mathrm{r}$ & - & - & - & $p^{\mathrm{b}}$ & $n$ & $\mathrm{r}$ & - & - & - & $p^{\mathrm{b}}$ & $n$ & $\mathrm{r}$ & - & $p^{b}$ \\
\hline CFQ v. SART ${ }_{\text {commission }}$ & 25 & 0.11 & & & & 0.61 & 32 & 0.18 & & & & 0.32 & 31 & -0.09 & & 0.64 \\
\hline CFQ v. SART omission & 25 & 0.09 & & & & 0.68 & 32 & 0.19 & & & & 0.3 & 31 & -0.31 & & 0.09 \\
\hline
\end{tabular}

${ }^{a} p$ Value of the difference with control participants.

${ }^{\mathrm{b}}$ Within-group $p$ value for the correlation. 


\section{Table 4}

Data from first session only

\begin{tabular}{|c|c|c|c|c|c|c|c|c|c|c|}
\hline \multirow[t]{2}{*}{ Descriptive statistics } & \multicolumn{6}{|c|}{ TBI participants-valid data } & \multicolumn{4}{|c|}{ Uninjured control participants } \\
\hline & $n$ & Mean & Range & S.D. & $\begin{array}{l}\text { Effect } \\
\text { size }\end{array}$ & $p^{a}$ & $n$ & Mean & Range & S.D. \\
\hline SART $_{\text {commission }}$ & 13 & 7.4 & $2-16$ & 4.5 & 0.25 & 0.48 & 35 & 6.4 & $1-16$ & 4 \\
\hline $\mathrm{SART}_{\text {omission }}$ & 13 & 5.1 & $0-13$ & 5.2 & 0.09 & 0.75 & 35 & 4.3 & $0-51$ & 10.4 \\
\hline $\mathrm{SART}_{\mathrm{RT}}$ & $\begin{array}{l}43 \\
5\end{array}$ & 432 & $259-545$ & 80.7 & 0.84 & 0.02 & 35 & 370 & $237-574$ & 79.2 \\
\hline CFQ & 12 & 11.2 & $1-24$ & 6.7 & 0.52 & 0.18 & 31 & 8.1 & $0-25$ & 5.5 \\
\hline \multirow[t]{2}{*}{ Correlations } & \multicolumn{10}{|c|}{ TBI participants-valid data } \\
\hline & $n$ & $\mathrm{r}$ & - & - & - & $p^{\mathrm{b}}$ & $n$ & $\mathrm{r}$ & - & $p^{\mathrm{b}}$ \\
\hline CFQ v. SART commission & 12 & 0.2 & & & & 0.54 & 31 & -0.05 & & 0.8 \\
\hline CFQ v. SART omission & 12 & 0.31 & & & & 0.32 & 31 & -0.27 & & 0.14 \\
\hline
\end{tabular}


Fig. 1

(A) Shows the distribution of RTs on correct trials, collapsed across two testing sessions for a representative control participant.

(B) Shows a similar distribution across three testing session for a participant with TBI who was included in the analysis of participants with valid data. Although the distribution is shifted to the right compared to the control participant, the full distribution appears visible.

(C) Shows a comparable distribution in a participant with TBI who was excluded from the analysis. Note that this individual's RT distribution ends abruptly on the right.
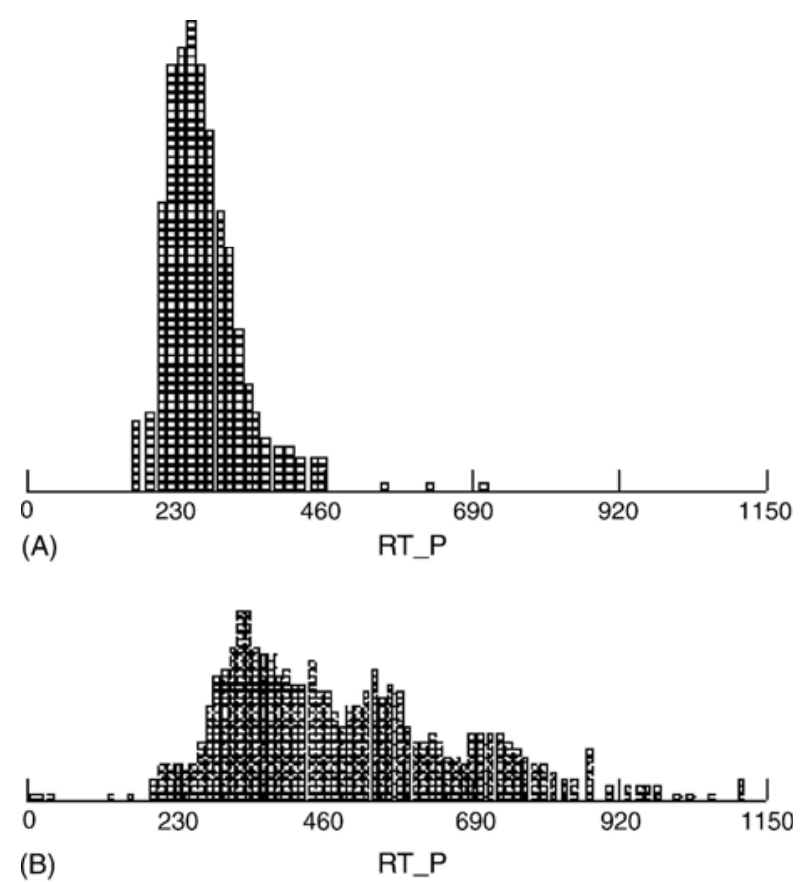

(B)

RT_P

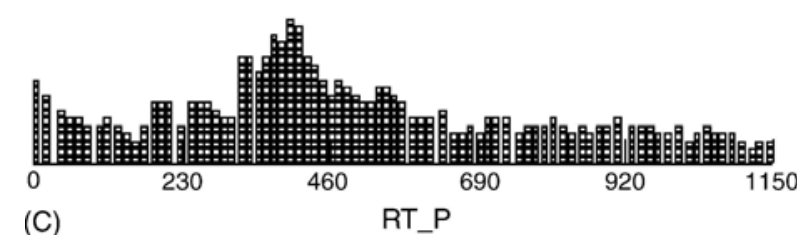


Fig. 2

(A) Shows the distribution of average rates of commission errors (across 3 sessions for participants with TBI and 2 sessions for control participants).

(B) Shows the distribution of commission errors in the first session for each group. Considerable overlap can be seen between the two distributions.
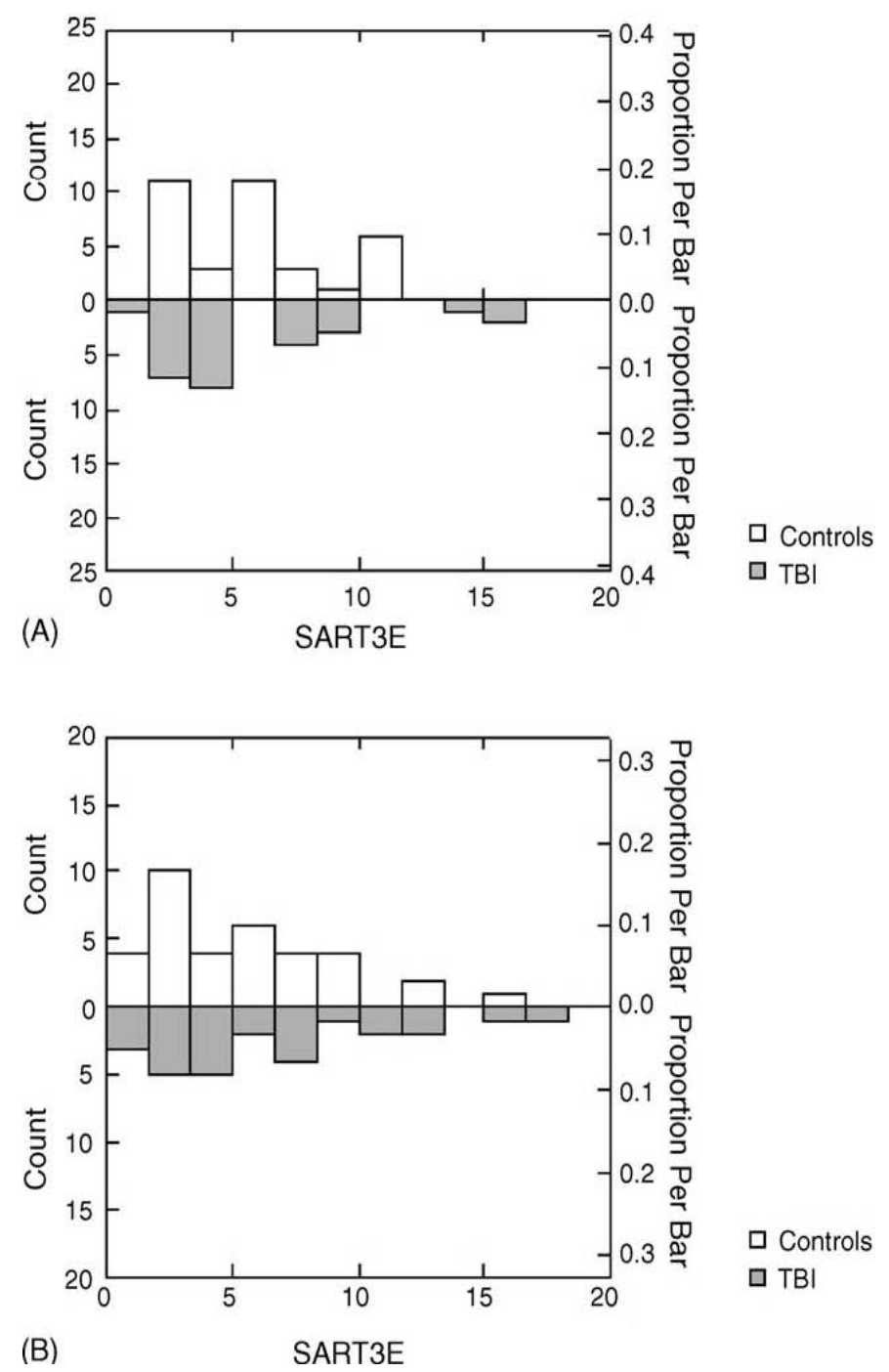